\title{
Assess the Practices of Nurses Regarding Oral Care of Intubated Patients in ICU
}

\author{
Hussna Khan ${ }^{1} \quad$ Kousar Perveen ${ }^{2} \quad$ Muhammad Afzal $^{3} \quad$ 'Dr. Syed Amir Gilani ${ }^{4}$ \\ 1. Student. The University of Lahore \\ 2. Assistant Professor, The University of Lahore \\ 3. Associate Professor. The University of Lahore \\ 4. Dean faculty of Allied Health Sciences. The University of Lahore
}

\begin{abstract}
Mouth care is very important for everyone. Good mouth care is preventing from bad breath, oral infection, teeth infection and oral mucositis. Good oral care is maintaining the good overall health. Nurses will not give mouth care to intubated clients than clients will get many other oral infections due to poor oral care.Aim of the current study is to assess critical care nurses' practices related to mouth care of mechanically ventilated with the equivalent factors. This was a descriptive cross-sectional study done in 15Feraury to 15March 2020 in Government hospital. A total of 152 critical care nurses were included in the study through convenient sampling technique. Data was collected through checklist by researcher.Result of the study revealed that out of 152 participants, $60.5 \%(n=92)$ participants washed their hand prior to given oral care to the patient and $39.5 \%(n=60)$ do not washed their hand prior to given oral care to the patient which show poor practice. Finding of the study also show that out of 152 participants, $47.37 \%(n=72)$ participants elevated head of the bed to at least 30 degree unless contraindicated and $52.63 \%(80)$ respondent not do such practices. Mouth care is a standard procedure. The presence of different mouth care practices demonstrates that there is a need of a standardized mouth care protocol.This study has offered significant understanding of nurse's practice regarding oral care of intubated patients in ICU and has identified regions for future improvement in our government hospital.
\end{abstract}

Keywords: Nurses, ICU, Practice, Oral, Care, Intubated, Patients,Participants

DOI: $10.7176 / \mathrm{JHMN} / 77-06$

Publication date:July $31^{\text {st }} 2020$

\section{Introduction:}

Mouth care is very important for everyone. Good mouth care is preventing from bad breath, oral infection, teeth infection and oral mucositis. Good oral care is maintaining the good overall health. Nurses will not give mouth care to intubated clients than clients will get many other oral infections due to poor oral care. Personal dignity and Quality of life have been accounted to be influence by oral health. This impact gives off an impression of being progressively serious in patients who are hospitalized and medically undermined. Nutritional status of the patient is also effected due to deprived/poor mouth care or dysfunctions which is harmful for general health (Allen, 2016). Best quality of professional care needs to ICU patients because mostly they are intubated, and some patients which is to be feed only through a tubing, unconscious or having fever, which may result in dehydration and breathing through the mouth. It causes a modification in mouth greenery and infection bounty, following decrease in salivary viability. Growing microscopic organisms in the teeth provide environment to bacteria/germs which is the main source of pneumonia in mechanically ventilated patients (Scannapieco, 2015).

Before given mouth care to intubated patient certain things are necessary to do. Hand washing is the most important because it is the key step through which we can prevent infection. Use of personal protective equipment before giving mouth care plays an important role because self-safety is significant. Personal protective equipment includes gloves, mask and also use of gown if patient is in contact isolation. Whenever going to do suction of the intubated patient, patient must be hyper oxygenated because during suctioning patient saturation may drop. Before mouth care old tie should also be removed because it is also a source of infection. After using all these practice before mouth care use pediatric toothbrush and $1.5 \%$ hydrogen peroxide solution for cleaning patient mouth (Momin, 2013).

After giving mouth care suction of the oral cavity should be done and also change the tube side to another side of the mouth to present the patient from harm. Tube should be secure enough to not remove easily; cuff should be proper inflated to minimize the leakage. After all doing this moisture should be applied to mouth and lip and then last hand should be washed properly (Ibrahim, 2015) .

There are a few difficulties to giving effective oral health to intubated patients in critical care unit accounted that healthcare workers not giving priority to mouth care, Nurses are worry about giving harm or pain to clients, judgment of the healthcare workers that mouth care doesn't give basic clinical benefits to patient, patients' resistive behavior, shortage of healthcare workers, dread of removing or uprooting the tube, instigating infection and absence of materials need for mouth care (Garrouste, 2017).

Generally oral consideration in intubated patients in critical care is centered to prevent infection because 
mouth is the main source of entering microorganism instead of removing plaque from the teeth (Yeung, 2018). For routine cleaning of patient mouth cotton swab is commonly used for. In spite of the fact that cotton swabs can animate tissues from the mucosa successfully but insufficient for removing the particles adhere in the teeth (Berry, 2017).

Nurses want to utilize soft swabs as it needs minimal effort, more convenient than tooth brushing and more helpful. In a stressful and exceptionally mechanical basic consideration condition, oral care is viewed as a low need (Katherason, 2016). An examination show that 9 out of 10 medical attendants or nurses supported foam brushwood to wipes for cleaning mouth of mechanically ventilated of clients (Graves, 2017).

Oral and general health are related which impact each other through natural, mental, enthusiastic, and formative components. Intensive care units patients are totally rely upon the caregiver and practices followed by the nurse's impact the recuperation of patients to a great extent (Fowler, 2020). Oral health problems are generally hid by different genuine needs in critically sick patients. likewise, nursing staff seem to see oral health as the most difficult part of their work; subsequently, it has been low-need mediation (Ganganna, 2017). On the other hand nurses_must have to value the significance of oral heath, they should have a sound knowledge of bacterial colonization in the oropharynx prompting infections, for example, cardiovascular sickness, interminable obstructive respiratory illness, and ventilator-related pneumonia (VAP) in basically sick patients (Ibrahim, 2015).

Critically sick patients in the ICU are related with expanded morbidity, mortality, and hospital costs as patients are immunocompromised and at a high risk for contaminations. The general disease rate might be as high as half $60 \%$ in patients who stay in ICU for over 5 days and occurrence of VAP may go from $10 \%$ to $65 \%$ which could be a prime concern in ICU (Dodek, 2019).Hence, an intensive knowledge of the pathogenesis is fundamental among nurses as critically sick patients are dependent on them for clinical consideration. There is persuading proof that biofilms shaped on the oral surface and endotracheal tubes go about as a supply of microorganisms that cause VAP along these lines, oropharyngeal purification, and different techniques planned for forestalling this translocation must be emphasized (Ansari, 2018).

\subsection{Research Problem:}

Oral care is the most important and fundamental nursing movement and subsequently it is for the most part not a need than other part of care. Advancement of calm and wonderful odor, mouth care intervention additionally has 3 critical ventilator related risk factors. These are oral secretion, oro-pharyngeal colonization which can move to the sub glottal district and clearing of dental plaque (Booker, 2017).

A survey demonstrated that training of nurses that are carried out under research based improve tolerant results. Evidence proof work on, as per (Groves, 2009), " reconciliation of research proof skills, persistent requirements and qualities in passage of value, practical social insurance. "This infers it includes utilization effective practice to encourage medical dynamic. Client mouth cleanliness which is research proof help with initiating protections besides attacking infectious organisms. Therefore, Current study will assess the nurse's practices regarding mouth care of mechanically ventilated clients in critical care.

\subsection{Aim of the study:}

Aim of the current investigation is to evaluate critical care nurses' practices related to mouth care of mechanically ventilated with the equivalent factors. The expectation of the investigation is to make suggestion for clinical practice and education of critical care nurses. There are following research objectives.

- To assess ICU nurses 'practices regarding mouth care of intubated clients in Critically Care Unit.

- To assess the correlation between demographics data and performance of the nurses regarding mouth care.

\subsection{Significance of the Study:}

By giving mouth care helps removing infectious micro-organism collected in the oral cavity which give way to pneumonia caused due to mechanical ventilator. Current investigation assesses level of knowledge of healthcare worker on the significance of mouth care which significantly influences their practices. "Healthcare worker needs to learn about mouth care and must have more sound knowledge and give mouth care to mechanically ventilated clients regularly which enhance their practices"(Lion, 2018). This help with enhancing excellence care given to critical care patients which ultimately increase patient comfort level, decreasing_mortality rates, long stay of hospital and cost.

\subsection{Conceptual Framework:}

The study will assume one kind of independent variable for example nurses practice and oral care is dependable variables. Oral care itself will be considered as dependent variable as above the independent variables may influence the nurses practices. The dependency and independency of the variables may be illustrated as follows: 
Fig 1

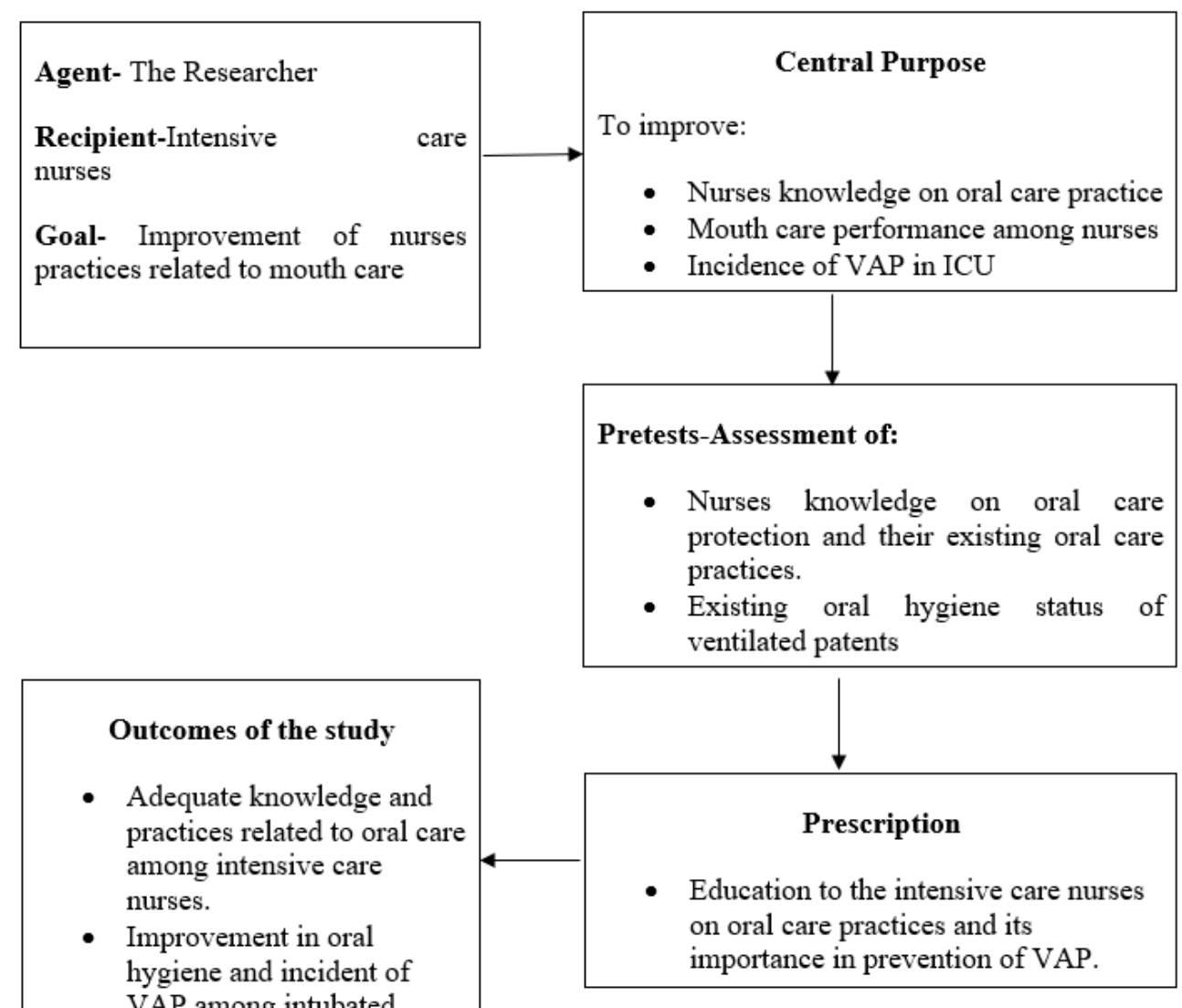

(Sonia, 2015)

Sonia adopted this model from Ernestine Wiedenbach's prescriptive theory as the basis for its conceptual framework. (Also called "The helping art of clinical nursing"). This theory focuses on three main factors: The central purpose, the prescription \& the realities. Fig 1: Conceptual Framework based on Wiedenbach's Prescriptive Theory (1990). The framework is about the practices of nurses related to mouth care of mechanically ventilated clients. The main agent in the framework is the researcher who wants to observe the nurse's practices working in ICU. The purpose is to enhance knowledge of the nurses regarding oral care of intubated patients in ICU through which their practice improved. This achieved only if the researcher assesses or observe the nurses practice prior to education and to know that nurses give proper oral care to intubated patient or not and also to assess their knowledge and practice about ventilated associated pneumonia. The researcher assessed the exciting oral hygiene status of the intubated patient. After doing this the researcher conduct education session to the ICU nurses regaining oral care practices and prevention of VAP. After giving education to ICU nurses their knowledge and practice improved and oral hygiene status of the intubated patients also improved (Sonia, 2015).

\section{Literature Review}

This area will explore the review of literature about the current study. It will cover many things related to practices of nurses regarding oral care like ventilator associated pneumonia, current guideline, evidence base practice, oral consideration. The key reason for the writing survey is to assist the analyst with building genuine structure for the examination.A study directed by Sazlin in 2016 which explained the type and recurrence of mouth care given to mechanically ventilated patients in critical care in Malaysia government hospital. Finding of study demonstrated recurrence system for mouth care characteristic in healthcare worker. Despite the way that current investigation was simply perform in four critical care units at single hospital; it given essential information into healthcare worker regarding mouth care practice and their knowledge and expectation of pneumonia in mechanically ventilated clients, the study result also show that most of the nurses $60 \%$ do not wash their hand before and after oral care given to intubated patient and 55\% do not uses proper PPEs and recognized areas enhancement in future (Yeung, 2018). Outcomes of the study also show that healthcare worker always like to use forceps and swab cotton instead of brush uses for teeth (toothbrush) for mouth care of clients. Generally, $73.4 \%$ of the 124 healthcare workers use forceps and swab for mouth care practice. Healthcare workers feel shy to give mouth care or use brushes for clients who are mechanically ventilated considering the way that endotracheal tube may oblige access 
to the oral care. Washing hand and utilization of personal protective equipment is significant before giving oral care to the patient. ICU nurses may also feel fear of removing or displacing the mechanical ventilation tube while given mouth care to intubated_patients. One more purpose not utilizing brushes may be the lack of knowledge of healthcare worker and new research finding; right now, healthcare worker not having any kind of effect the latest oral care practices (Sazlin, 2016).

The main purpose of mouth care in critical care is to reduce_inconvenience (Sona, 2018). Oral consideration is a major nursing development which elevates well being and patient feel more comfortable. Mouth care rules made by various organizations and now a day accessible on the web. Critical care nurses association of America (AACN) Practice make a standard of comprehensive mouth care for critically sick clients, recommends the usage of a soft brush after $12 \mathrm{hrs,}$, also utilization of mouth cream after 2 to 4 hours to lips (Care, 2017).

Another study conducted by (Ibrahim, 2015) in Sudan in which they describe that the majority of the healthcare worker gotten practice showed that $92 \%$ of their training was a basic nursing preparation. It may be challenging, as mouth care of mechanically ventilated clients need various information and practice as compared to ward clients. Old tie of the endotracheal tube should be free and change if it is visibility soiled with secretion. In Africa fundamental nursing was main cause of training for 35 healthcare worker $(36.5 \%)$, however 22 healthcare worker $(22.9 \%)$ gotten practice while simultaneously finishing their postgraduate program. 2 healthcare worker $(2.1 \%)$ communicated that their main source of practice had been during continuing with instructive exercises, for instance, interest of the nurses, and 10 nurses (10.4\%) showed that main source of education was clinical rotation in different ward of the hospital (Cindy, 2015).

A Study in India shows that nurses love their work and responsibility toward patients' health, but they were hesitant to give mouth care in mechanically ventilated patients due to the fear of tube dislodgment and removing. As a rule, the mechanical check was represented as a huge barrier toward care $(76.5 \%)$. Fear of dislodging or removing the endotracheal tube is a real concern and can be dangerous. The shortage of staffing decrease patientnurse contact time because one nurse can look after many patients and cannot give proper time to single patient due to different tasks, which as a huge factor in giving quality health. When nurses are overburdened, they cannot focus to oral care of the patient (Vidya, 2020).

\section{Methodology:}

\subsection{Research Design:}

The present study was hospital based and cross-sectional expressive investigation, and it was done in March 2020, to assess the practices of nurses regarding mouth care of mechanically ventilated patients in critical area.

\subsection{Population of the study:}

Study populace of the present study was the nurses of Government hospital Lahore. The nurses who consented to take an interest was experience the assent forms, disclosing to them the advantages and dangers of taking part in the study. Deliberate investment was supported. The study population was being 245 nurses.

\section{Intrinsic Criteria:}

All those nurses working in ICU of the selected hospital was included in the study.

\section{Extrinsic Criteria:}

All other nurses who work out of ICU and those who are not willing to participate in the study were excluded from my study.

\subsection{Sample and sampling techniques:}

Information was gathered from 152 nurses through convenient sampling techniques. The individuals who meet the consideration criteria were incorporated into the investigation and the individuals who do not meet the criteria won't be the part of the study or research.

\section{Research Instrument:}

The study instrument was consisting of two segments. Section A is involved socio statistic information. While segment B includes different multiple-choice questions with respect to the Practice of nurses regarding mouth care of intubated clients in critical care.

\section{Data Collection:}

Information was gathered from ICU nurses of Government hospital Lahore. The information was gathered with the help of different associates inside a predefined time period. Data was collected through well-organized checklist which looked for such data as age, experience, educational status, kind of conveyance and knowledge and practice regarding mouth care of mechanically ventilated patients in critical area. This checklist was completed by researcher from 152 participants through convenient sampling method.

\section{Data Analysis:}

Factual investigation was done utilizing SPSS for Windows adaptation 21. The collected data was analyzing through spss version 20.0. And data was computed using frequency, tables and charts. The connection between 
the three factors scores and socio-statistic factors was tried by utilizing relationship and chi-square test. The centrality level for all measurable investigation was set at 0.05 .

\section{Results:}

This chapter includes 5 portions of analysis. Section A was demographic analysis. It gives us details of demographic questions. Descriptive analysis was used for other different section, section B include question Related to Practices Prior to Oral Care, Section C questions related to Oral Care Event, section D related Post-Oral Care Practices and section E have question related to Patient Monitoring and Care. It assesses the practices of nurses regarding oral care of intubated patients in ICU.

CHECKLIST OF NURSING PRACTICE ON ORAL CARE OF INTUBATED PATIENTS

Section A: Socio-demographic characteristics of study participants

\begin{tabular}{|c|c|c|c|c|}
\hline Sr.no & \multicolumn{2}{|c|}{ Socio-demographic characteristics of study participants } & YES & NO \\
\hline \multirow{2}{*}{1} & \multirow[t]{2}{*}{ Organization } & Government & $100 \%$ & \\
\hline & & Private & $00 \%$ & \\
\hline \multirow[t]{3}{*}{2} & \multirow{3}{*}{ Age } & $1) 25-31$ & $47.37 \%$ & \\
\hline & & 2) $32-38$ & $32.89 \%$ & \\
\hline & & 3) $39-45$ & $19.74 \%$ & \\
\hline \multirow[t]{3}{*}{3} & \multirow{3}{*}{ Qualification } & 1) General Nursing & $26.3 \%$ & \\
\hline & & 2) BS. Degree & $73.6 \%$ & \\
\hline & & 3) MS. Degree & $00 \%$ & \\
\hline \multirow[t]{2}{*}{4} & \multirow[t]{2}{*}{ Gender } & Male & $00 \%$ & \\
\hline & & Female & $100 \%$ & \\
\hline \multirow[t]{3}{*}{5} & \multirow[t]{3}{*}{ Designation } & 1) Head Nurse & $00 \%$ & \\
\hline & & 2) Registered Nurse & $80.3 \%$ & \\
\hline & & 3) Student Nurse & $19.7 \%$ & \\
\hline \multirow[t]{3}{*}{6} & \multirow[t]{3}{*}{ Experience } & 1) $<1$ year & $14.4 \%$ & \\
\hline & & 2) $1-10$ year & $52.6 \%$ & \\
\hline & & $3)>10$ years & $32.8 \%$ & \\
\hline
\end{tabular}

Section B: Practices Prior to Oral Care

\begin{tabular}{|c|l|c|c|}
\hline Sr.no & Question related to Practices Prior to Oral Care & YES & NO \\
\hline 1 & Hands are washed. & $60.5 \%$ & $39.5 \%$ \\
\hline 2 & Personal protective equipment's (e.g. Gloves) are worn. & $60.5 \%$ & $39.5 \%$ \\
\hline 3 & Hyperoxygenation/hyperinflation prior to suctioning. & $34.21 \%$ & $65.79 \%$ \\
\hline 4 & Suction endotracheal tube. & $53.95 \%$ & $46.5 \%$ \\
\hline 5 & Old tape and ties are loosened and removed & $51.32 \%$ & $48.62 \%$ \\
\hline 6 & $\begin{array}{l}\text { If patient is nasally intubated, the nurse cleaned around endotracheal tube } \\
\text { using saline-soaked gauze or cotton swabs. }\end{array}$ & $37.50 \%$ & $62.50 \%$ \\
\hline 7 & $\begin{array}{l}\text { If patient is orally intubated oropharyngeal airway or mouth Gag (acting as } \\
\text { bite-block) are removed. }\end{array}$ & $61.84 \%$ & $38.16 \%$ \\
\hline
\end{tabular}

\section{Section C: The Oral Care Event}

\begin{tabular}{|l|l|c|c|}
\hline Sr.no & Question related to The Oral Care Event & YES & NO \\
\hline 8 & $\begin{array}{l}\text { Perform oral care using Pediatric toothbrush or Adult (soft) toothbrush at least } \\
\text { twice a day. Gently brush patient's teeth to clean and remove plaque from teeth. }\end{array}$ & $61.84 \%$ & $38.16 \%$ \\
\hline 9 & $\begin{array}{l}\text { Oral swab with 1.5\% Hydrogen peroxide solution to clean mouth every 2 to 4 } \\
\text { hours. }\end{array}$ & 0 & $100 \%$ \\
\hline
\end{tabular}


Section D: Post-Oral Care Practices

\begin{tabular}{|c|l|c|l|}
\hline Sr.no & Question related to Post-Oral Care Practices & YES & NO \\
\hline 10 & Suction oral cavity/pharynx. & $72.37 \%$ & $27.63 \%$ \\
\hline 11 & Oral tube was moved to the other side of the mouth. & $54.61 \%$ & $45.39 \%$ \\
\hline 12 & $\begin{array}{l}\text { Oropharyngeal airway (bit-block)was replaced along the endotracheal tube } \\
\text { (To prevent biting, minimize pressure areas on lips, tongue, and oral cavity). }\end{array}$ & $50.66 \%$ & $49.34 \%$ \\
\hline 13 & $\begin{array}{l}\text { The nurse ensured proper tube cuff inflation using minimal leak volume or } \\
\text { minimal occlusion volume. }\end{array}$ & $60.53 \%$ & $39.47 \%$ \\
\hline 14 & $\begin{array}{l}\text { After oral care, the nurse reconfirm tube placement, and note position of tube } \\
\text { at teeth or naris (common tube placement at teeth is 21 cm for women and 23 } \\
\text { cm for men }\end{array}$ & $47.37 \%$ & $52.63 \%$ \\
\hline 15 & $\begin{array}{l}\text { After oral care, the nurse secure the endotracheal tube in place (according to } \\
\text { institutional standard) (to prevent inadvertent dislodgment of the tube) }\end{array}$ & $50.66 \%$ & $49.34 \%$ \\
\hline 16 & $\begin{array}{l}\text { With each cleansing, applying a mouth moisturizer to the oral mucosa and lips } \\
\text { to keep tissue moist? }\end{array}$ & $27.63 \%$ & $72.37 \%$ \\
\hline 17 & Hands are washed & $47.30 \%$ & $52.63 \%$ \\
\hline
\end{tabular}

Section E: Patient Monitoring and Care

\begin{tabular}{|c|c|c|c|}
\hline Sr.no & Question related to Patient Monitoring and Care & YES & NO \\
\hline 18 & Head of the bed elevated at least 30 degree unless contraindicated. & $44.08 \%$ & $55.92 \%$ \\
\hline 19 & Suctioning endotracheal tube if clinically indicated. & $47.30 \%$ & $52.63 \%$ \\
\hline 20 & The nurse monitored the amount, type and color of secretions. & $27.63 \%$ & $72.37 \%$ \\
\hline 21 & If patient is nasally intubated, the nurse monitor for nasal drainage. & $37.50 \%$ & $62.50 \%$ \\
\hline 22 & The nurse assesses the oral cavity and lips at least every 8 hours. & $37.50 \%$ & $62.50 \%$ \\
\hline 23 & $\begin{array}{l}\text { During oral care, the nurse assesses buildup of plaque on teeth or potential } \\
\text { infection related to oral abscess? }\end{array}$ & $34.21 \%$ & $65.79 \%$ \\
\hline 24 & $\begin{array}{l}\text { The nurse reconfirm tube placement, and note position of tube at teeth or naris. } \\
\text { Retape or secure endotracheal tube at least once per day for soiled or loose } \\
\text { securing devices. }\end{array}$ & $50.66 \%$ & $49.34 \%$ \\
\hline
\end{tabular}

\section{Discussion:}

This cross sectional assess the practices of nurses regarding oral care of intubated patients in ICU among 152 participants which is my sample size, this study was done in Government Hospital Lahore with the help of convenient sampling, the questionnaire was distributed among participant which result show that most participants have good practices and few have poor practices regarding oral care of intubated patients in ICU. Study result show in Table and figure number 7 that out of 152 participants, $60.5 \%(n=92)$ participants washed their hand prior to given oral care to the patient and $39.5 \%(n=60)$ participants do not washed their hand prior to given oral care to the patient. Table and figure number 8 also shows that out of 152 participants, $53.95 \%(n=82)$ participants uses proper personal protective equipments prior to given oral care to the patient and $46.05 \%(n=70)$ participants do not uses proper personal protective equipments prior to given oral care.

A similar study conducted by (Yeung, 2018) in four critical care units at single hospital; which result is linear with the current study and give essential information into healthcare worker regarding mouth care practice and their knowledge , the study result also show that most of the nurses $60 \%$ do not wash their hand before and after oral care given to intubated patients and 55\% do not uses proper PPEs and recognized areas enhancement in future.

The current study revealed that that out of 152 participants, only $22.37 \%(n=34)$ participants performing oral care using Pediatric toothbrush or Adult (soft) toothbrush at least twice a day and Gently brush patient's teeth to clean and remove plaque from teeth and most of the participants $77.63 \%(n=118)$ do not have such practices.

Study conducted by (Sazlin, 2016) which finding is similar to the present study and shows that healthcare worker always like to use forceps and swab cotton instead of brush uses for teeth (toothbrush) for mouth care of clients. Generally $73.4 \%$ of the 124 healthcare workers use forceps and swab for mouth care practice. Healthcare workers feel shy to give mouth care or use brushes for clients who are mechanically ventilated considering the way that endotracheal tube may oblige access to the oral care. Washing hand and utilization of personal protective equipment is significant before giving oral care to the patient. ICU nurses may also feel fear of removing or displacing the mechanical ventilation tube while given mouth care to intubated_patients. One more purpose not utilizing brushes may be the lack of knowledge of healthcare worker and new research finding; right now, healthcare worker not having any kind of affect the latest oral care practices (Sazlin, 2016).

The present study result also revealed that out of 152 participants, only $47.37 \%(n=72)$ participants after oral care, reconfirm tube placement, and note position of tube at teeth or naris and most of the participants $52.63 \%$ 
$(\mathrm{n}=80)$ participants not doing this practices because of fear of dislodging the tube . Current study also show that only $27.63 \%(n=42)$ participants applied moisture to the oral cavity/lips and most of the respondents $72.37 \%(110)$ do not apply moisturizer to oral mucosa after oral care of the patients which predicted poor practices in government hospitals.

A Survey conducted in India by (Vidya, 2020) shows that most of the nurses $76.5 \%$ were hesitant to give mouth care in mechanically ventilated patients due to the fear of tube dislodgment and removing. Fear of dislodging or removing the endotracheal tube is a real concern and can be dangerous. The shortage of staffing decrease patient-nurse contact time because one nurse can look after many patients and cannot give proper time to single patient due to different tasks, which as a huge factor in giving quality health. When nurses are overburdened, they cannot focus to oral care of the patient (Vidya, 2020).

\section{Conclusion}

Mouth care is a standard procedure in our hospitals; Furthermore, the frequency and kind of mouth care practice different among healthcare workers in the units. The presence of different mouth care practices demonstrates that there is a need of a standardized mouth care protocol that incorporates tooth brushing and utilization of chlorhexidine mouthwash. Besides, having chlorhexidine mouthwash and legitimate toothbrushes accessible in the unit's stock may help with actualizing proof based practice and help to improve patients' result. This study has offered significant understanding of nurse's practice regarding oral care of intubated patients in ICU and has identified regions for future improvement in our government hospital.

\section{Recommendation}

Nurses working in ICU in the current study were not interested to the suggestions for ETT and oral care as indicated by $\mathrm{CDC}$ in their present practice and subsequently need continuous instruction identified with proof base ETT and care protocol. Nurses are deprived for clinical practice to improve knowledge, skills and capability of oral care especially brushing teeth, suctioning, oral evaluation, infection control practices and oxygenation. Collective cooperation with dental hygienists improves knowledge and capacities related to oral care. The utilization of standard oral practices improves patient care quality and assesses nurses in giving effective oral care.

Unit protocols should be reviewed regularly as updates and new evidence for best practice are constantly emerging and ICU nurses should be educated on updated protocols. ICU nurses should be encouraged to engage in reading journal articles. Articles on oral care guidelines and developments should be discussed in unit meetings as part. Nursing educators and clinical facilitators must incorporate strategies of oral care evidence-based practice into the ICUs and use learning opportunities to raise the topic.

\section{References:}

Allen. (2016). Factors Affecting Quality of Oral Care in Intensive Care Units. Journal of Advanced Nursing, $45(12), 456-462$

Ansari.(2018). Guideline for prevention of nosocomial pneumonia. The hospital infection control practices advisory committee, centers for disease control and prevention. Infect Control Hosp Epidemiol, 15(7), 587627.

Berry.(2017). Systematic literature review of oral hygiene practices for intensive care patients receiving mechanical ventilation. Am Journal of Crit Care, 4(3), 552-562.

Booker. (2017). Systematic literature review of oral hygiene practices for intensive care patients receiving mechanical ventilation., international journal of critical care(5), 1.

Care, A. A. o. C. (2017). ACCN Practice Alert: Oral Care for Patients at risk for Ventilator-associated pneumonia. American Association of Critical Care., 4(2), 34-45

Cindy. (2015). Oral Health and Care in the Intensive Care Unit: State of Science. American Journal for Critical Care, 13(5), 25-34.

Dodek. (2019). Evidence-based clinical practice guideline for the prevention of ventilator-associated pneumonia. International journal of Medicine, 6(2), 305-313.

Fowler. (2020). Periodontal disease and its association with systemic disease. international journal of infection control, 8(2), 85-92.

Ganganna. (2017). Opinion of dentists and gynecologists on the link between oral health and preterm low birth weight: Preconception care-treat beyond the box. J Indian Soc Pedod, 3(1), 123-131.

Garrouste. (2017). Oropha- ryngeal or Gastric Colonization and Nosocomial Pneumonia in Adult Intensive Care Unit Patients. American Journal of respiratory critical care, 8(2), 145-150.

Graves. (2017). The effect of healthcare-acquired infection on length of hospital stay and cost. Infect Control Hosp Epidemiol, 11(7), 280-292.

Groves, B. a. (2009). The of nursing research in patient care. Journal of Intensive Care Medicine, 3(1), 54-62.

Ibrahim. (2015). Nurses' knowledge, attitude and practice of oral care for intensive care unit patients. . Open 
Journal of Stomatol, 5(2), 79-86.

Katherason. (2016). Ventilator-associated nosocomial pneumonia in intensive care units in Malaysia. Journal Infect Dev Ctries, 2(3), 704-710.

Lion. (2018). Factors Affecting Quality of Oral Care in Intensive Care Units. Journal of Advanced Nursing. Infect Control Hosp Epidemiol, 15(6), 454-462.

Momin. (2013). Exploring the Competency of the Jordanian Intensive Care Nurses towards Endotracheal Tube and Oral Care Practices for Mechanically Ventilated Patients:An Observational Study. Global Journal of Health Science, 5(1), 125-135.

Sazlin. (2016). Beyond comfort: Oral hygiene as a critical nursing activity in the intensive care unit. Journal of Intensive Crit Care Nurs, 9(3), 318-328.

Scannapieco, F. A., Stewart, E.M. and Mylotte, J.M. (2015). Colonization of Dental Plaque by Respiratory Pathogens in Medical Intensive Care Patients. Journal Critical Care Medicine, 20(3), 740-745.

Sona. (2018). The impact of simple, Low cost oral care protocol on ventilator- associated pneumonia rates in surgical intensive care unit. Journal of Intensive Care Medicine,, 17(8), 54-62.

Sonia. (2015). Effect of education related to oral care practices on nurses' knowledge, practice and clinical outcomes of mechanically ventilated patients in Dubai. International Journal of Nursing Research and Practice, 2(1), 1510-1519

Vidya. (2020). Oral hygiene care in the pediatric intensive care unit: Practice recommendations. Pediatric nursing, $3(2), 85-96$.

Yeung. (2018). An exploration of factors affecting Hong Kong ICU nurses in providing oral care. journal of clinical nursing and criticial care, 19(7), 3063-3072.

Dear Madam

\section{Questionnaire}

This survey is being done by Mrs.ABC in the supervision of XYZ, Department of Lahore School of Nursing, at The University of Lahore, Lahore. The purpose of this survey is to collect information about "To assess the practices of nurses regarding oral care of intubated patients in ICU”. This survey is only for the academic purpose and the personal identity will be kept confidential. Thank you for your valuable time and opinion.

Regards,

Hussna Khan

(BPSN02183019)

hussnakhan.hk@gmail.com

CHECKLIST OF NURSING PRACTICE ON ORAL CARE OF INTUBATED PATIENTS

Section A: Socio-demographic characteristics of study participants

\begin{tabular}{|c|c|c|c|c|}
\hline Sr.No & & Socio-demographic characteristics of study participants & YES & NO \\
\hline \multirow[t]{2}{*}{1} & \multirow[t]{2}{*}{ Organization } & Government & 1 & 2 \\
\hline & & Private & 1 & 2 \\
\hline \multirow[t]{3}{*}{2} & \multirow{3}{*}{ Age } & 1)25-31 & 1 & 2 \\
\hline & & 2) $32-38$ & 1 & 2 \\
\hline & & 3) $39-45$ & 1 & 2 \\
\hline \multirow[t]{3}{*}{3} & \multirow{3}{*}{ Qualification } & 1) General Nursing & 1 & 2 \\
\hline & & 2) BS. Degree & 1 & 2 \\
\hline & & 3) MS. Degree & 1 & 2 \\
\hline \multirow[t]{2}{*}{4} & \multirow[t]{2}{*}{ Gender } & Male & 1 & 2 \\
\hline & & Female & 1 & 2 \\
\hline \multirow[t]{3}{*}{5} & \multirow[t]{3}{*}{ Designation } & 1) Head Nurse & 1 & 2 \\
\hline & & 2) Registered Nurse & 1 & 2 \\
\hline & & 3) Student Nurse & 1 & 2 \\
\hline \multirow[t]{3}{*}{6} & \multirow[t]{3}{*}{ Experience } & 1) $<1$ year & 1 & 2 \\
\hline & & 2) $1-10$ year & 1 & 2 \\
\hline & & 3) $>10$ years & 1 & 2 \\
\hline
\end{tabular}


Section B: Practices Prior to Oral Care

\begin{tabular}{|c|c|c|c|}
\hline Sr.no & Question related to Practices Prior to Oral Care & YES & NO \\
\hline 1 & Hands are washed. & 1 & 2 \\
\hline 2 & Personal protective equipment's (e.g. Gloves) are worn. & 1 & 2 \\
\hline 3 & Hyperoxygenation/hyperinflation prior to suctioning. & 1 & 2 \\
\hline 4 & Suction endotracheal tube. & 1 & 2 \\
\hline 5 & Old tape and ties are loosened and removed & 1 & 2 \\
\hline 6 & $\begin{array}{l}\text { If patient is nasally intubated, the nurse cleaned around endotracheal tube using saline- } \\
\text { soaked gauze or cotton swabs. }\end{array}$ & 1 & 2 \\
\hline 7 & $\begin{array}{l}\text { If patient is orally intubated oropharyngeal airway or mouth Gag (acting as bite-block) } \\
\text { are removed. }\end{array}$ & 1 & 2 \\
\hline
\end{tabular}

\section{Section C: The Oral Care Event}

\begin{tabular}{|c|l|c|c|}
\hline Sr.no & Question related to The Oral Care Event & YES & NO \\
\hline 8 & $\begin{array}{l}\text { Perform oral care using Pediatric toothbrush or Adult (soft) toothbrush at least twice } \\
\text { a day. Gently brush patient's teeth to clean and remove plaque from teeth. }\end{array}$ & 1 & 2 \\
\hline 9 & Oral swab with 1.5\% Hydrogen peroxide solution to clean mouth every 2 to 4 hours. & 1 & 2 \\
\hline
\end{tabular}

Section D: Post-Oral Care Practices

\begin{tabular}{|c|c|c|c|}
\hline Sr.no & Question related to Post-Oral Care Practices & YES & NO \\
\hline 10 & Suction oral cavity/pharynx. & 1 & 2 \\
\hline 11 & Oral tube was moved to the other side of the mouth. & 1 & 2 \\
\hline 12 & $\begin{array}{l}\text { Oropharyngeal airway (bit-block)was replaced along the endotrachealtube } \\
\text { (to prevent biting, minimize pressure areas on lips, tongue, and oralcavity). }\end{array}$ & 1 & 2 \\
\hline 13 & $\begin{array}{l}\text { The nurse ensured proper tube cuff inflation using minimal leak volume or minimal } \\
\text { occlusion volume. }\end{array}$ & 1 & 2 \\
\hline 14 & $\begin{array}{l}\text { After oral care, the nurse reconfirm tube placement, and note position of tube at teeth } \\
\text { or naris (common tube placement at teeth is } 21 \mathrm{~cm} \text { for women and } 23 \mathrm{~cm} \text { for men }\end{array}$ & 1 & 2 \\
\hline 15 & $\begin{array}{l}\text { After oral care, the nurse secure the endotracheal tube in place (according to } \\
\text { institutional standard) (to prevent inadvertent dislodgment of the tube) }\end{array}$ & 1 & 2 \\
\hline 16 & $\begin{array}{l}\text { With each cleansing, applying a mouth moisturizer to the oral mucosa and lips to keep } \\
\text { tissue moist? }\end{array}$ & 1 & 2 \\
\hline 17 & Hands are washed & 1 & 2 \\
\hline
\end{tabular}

\section{Section E: Patient Monitoring and Care}

\begin{tabular}{|c|l|c|c|}
\hline Sr.no & Question related to Patient Monitoring and Care & YES & NO \\
\hline 18 & Head of the bed elevated at least 30 degree unless contraindicated. & 1 & 2 \\
\hline 19 & Suctioning endotracheal tube if clinically indicated. & 1 & 2 \\
\hline 20 & The nurse monitored the amount, type and color of secretions. & 1 & 2 \\
\hline 21 & If patient is nasally intubated, the nurse monitor for nasal drainage. & 1 & 2 \\
\hline 22 & The nurse assesses the oral cavity and lips at least every 8 hours. & 1 & 2 \\
\hline 23 & $\begin{array}{l}\text { During oral care, the nurse assesses buildup of plaque on teeth orpotential infection } \\
\text { related to oral abscess? }\end{array}$ & 1 & 2 \\
\hline 24 & $\begin{array}{l}\text { The nurse reconfirm tube placement, and note position of tube at teeth or naris. } \\
\text { Retape or secure endotracheal tube at least once per day for soiled or loose securing } \\
\text { devices. }\end{array}$ & 1 & 2 \\
\hline
\end{tabular}

